\title{
An Analysis of Linguistic Differences between Different Genders of Chinese Children from the Communicative Strategies*
}

\author{
Yingying Ma \\ School of Foreign Language, Zunyi Medical University, Zunyi, China
}

\begin{abstract}
This research investigates gender difference in verbal interaction of Chinese Children around 3 and a half years old. It based on corpus linguistic study and focused on comparing the MLU (Mean Length of Utterance) and frequency of use of word parts between boys and girls, to find whether there are significant differences in language competence between boys and girls. Meanwhile, this research provides some practical strategies to facilitate the language learning process from the aspect of different genders.
\end{abstract}

Index Terms-gender difference, MLU (Mean Length of Utterances), frequency of use of word parts, communicative skills

\section{INTRODUCTION}

\section{Background}

The cognitive ideas of the Swiss psychologist Jean Piaget (1959) have been a major influence on the study of language development. Although Piaget died in 1980, his proposals continue to stimulate a great deal of interesting research on the relationship between language and thought in children. Like Chomsky, Piaget viewed the child as actively constructing language rather than simply imitating it. However, on the other hand, Piaget did not view the human mind as having a separate language processing capacity or any inborn knowledge about language like Chomsky. The study of child language in China didn't come to an age of development until 1978. Most researchers in this field are professors of psychology, and many researches revealed that the reasons why children's language development showed differences. From the middle of 1980s, some linguists like Professor Gui Shichun began his research in this field. However, most researches were focused on the characteristics of child language in different ages, and ignored the differences in communicative skills between boys and girls. Maccoby and Jacklin (1974) summarize from over 1,500 studied on gender differences of children's cognition, emotion and sociality, and report that girl's verbal ability is higher than boy's. Australian scholars also work out a precise tri-dimensional picture of human brain after anatomizing 30 brain organizes, which proves that there are much larger space in female's than male's brain for learning languages, reading and writing and getting knowledge. British researchers further prove that girls are verbally competent than boy since two years old, and this is determined by their genes, and it is believed that different genes produce different hormone, which leads to their different verbal abilities. Zhou Jing (2006) reports that boys tend to use more aggressive and assertive language than girls, and boys often use onomatopoetic words while girls often use the interjections. A parallel finding by Nohara (1996) reveals a tendency for boys to use no when correcting or prohibiting their playmates' behavior more often than girls. Another more notable finding reveals that girls provide explanations as to why they deny or reject their partners' propositions or suggestions more often than boys.

The Mean Length of Utterances (MLU)?

MLU is an effective way to weigh children's linguistic development. The research of Pan shows that complicated sentence structures make the length of sentences longer. Therefore, the MLU is a significant sign to weigh the complicated degree of the sentences, which can reflect children's language level directly. In our country, there are two ways which can calculate the mean length of children's utterances: one is taking the Chinese character as a standard of measurement, the other is taking the word as a standard of measurement. This research takes the Chinese character as a standard of measurement and calculate the mean length of children's utterances.

MLU of children can be found by calculating the total number of utterances used by children and dividing that number by the total number of utterances used by the same children. We can separately calculate MLU of boys and girls. When calculating MLU of children, the following points should be focused on: 1) Brown (1973) pointed that when calculating MLU, the repeated utterances can only be regarded as one utterance, so we should use [/] to mark the repeated utterances, which can be deleted when running the CLAN program. 2) [+Y] can be labeled as a mood word that can lonely be a sentence; $[+\mathrm{R}]$ can be marked as the meaningless utterances. However, the calculating program cannot delete such utterances automatically, so we should add some commands manually to delete the meaningless

\footnotetext{
* This paper is sponsored by China Scholarship Council.
} 
utterances. For example, mlu $+t^{*}$ chi $-\mathrm{s}$ " $[+\mathrm{R}]$ ”-s “ $[+\mathrm{Y}]$ ” $+\mathrm{f}^{*}$. cha. " $+\mathrm{t}^{*}$ chi” can only analyze children's utterances; "$\mathrm{s}$ " means the deletion of the content; " $\mathrm{f}$ " means the saving of the results. 3) If the obscure utterances should be contained when calculating the MLU, we should use "xx" instead of "xxx", because the CLAN system will ignore the marks of "xxx". After the calculation of data, we can go on performing independent t-test. With the help of SPSS13.0, the contrast between boys and girls in terms of the two different mean length of utterances will be conducted by using independent-samples t-test analysis, to examine whether there is a significant difference of the mean length of utterances between boys and girls. Based on the result of the t-test, we can compare the length of utterances between boys and girls.

This research aims at comparing girls' verbal interaction with boys', and finding the reasons why there are significant differences in language competence between boys and girls. It provides some ways which can be adopted to help children improve their expressive ability and offers some productive insights that will profoundly influence the child language development of different genders. The reason why we choose children around the age of three and a half years old is that most researchers think that the critical period is not up to the puberty but around three to four years old. It is until 1989 that the critical period was designated up to a certain age by Janet Werker from Canada. That's why we put our effort to analyze the early child language acquisition at the very beginning ages of the children.

\section{RESEARCH DESIGN}

\section{Research Overview}

This research aims at pursuing answers for the following two questions:

(1) What are the differences when the boys and girls interact with others with regard to the parts of speech?

(2) Are the boys' MLU (Mean Length of Utterances) significantly different from girls?

The software ICTCLAS is used for the automatic word segmentation and part-of-speech tagging in the corpus. So ICTCLAS can help us to tag the part-of-speech of children's speaking. Because of inaccuracy of pronunciation of children, child-direct language, and the self-creation words, researchers have to proofread the text manually after the automatic segmentation of ICTCLAS.

With regard to the comparison of mean length utterances between boys and girls, independent t-test can be adopted in this research to analyze the data that are calculated by CLAN system.

\section{Participants}

In the research, thirty-three children will be chosen, seventeen of which are boys and sixteen are girls whose ages are around three and a half years old.

\section{Corpus Construction}

We will record their half an hour conversations with adults and obtain 16.5 hours data. Because child language is so complicated that it cannot be distinguished by the automatic transcribed tools, we have to convert the video data to text files manually and then revise them and get about 120,000 characters, including more than 20,000 characters of children's. When converting the video data, we should obey the basic coding rule of CHAT. Then we can use CLAN program to analyze the text automatically. After the transcription of the data, we should use Microsoft Word to edit the text, and save it in the name of genders and acronyms of children's name. When we use the CLAN to analyze the text, we should save the text. For example, BLLT (B stands for the boy, and LLT is the acronyms of boy's name); GZJY (G stands for the girl, and ZJY is the acronyms of girl's name). At last, some databases are established, and the construction of the corpus provides a real foundation for the frequency of word-classes and mean length of utterances.

\section{Observation}

To collect more accurate linguistic data of children, the researcher should keep a close eye on progress. The researcher, therefore, should take part in parent-child activity every week, and observe children's language development. The purpose is to compare linguistic characteristics of boys with girls so as to investigate in which environment or which topic can stimulate children to express smoothly. It is important for observation to be systematic, thus, the researcher designs an observation checklist. The statements of observation checklist include children's interest, behavior, utterances, and the different reactions when boys and girls speak to different targets, for example, teachers, parents, fellows and strangers. When observing the conversations of children, the researcher should notice the gender differences consciously to find the linguistic characteristics between boys and girls.

\section{An interview}

In order to find more children's linguistic characteristics between boys and girls, the researcher should interview parents to know children's process of language learning, and the language environment that parents create for children. The researcher randomly interviews 6 parents, three of which are boys' parents and three are girls'. The interview is about some language activities parents designed for their children. There are several questions in this interview, such as "Do you often speak to your son/daughter, even some meaningless talk?" "Do you read the story for your son/daughter everyday, if yes, after reading the story, will you ask some questions for your children to lead them repeat the story?" "Do you use normal language to communicate with your children, rather than using the child-direct language?" "What do you think about your children's utterances, do they often use long sentences to speak or they just like using some short and illogical sentences to express themselves?" "Will your children imitate others' utterances when they heard some funny talk?" The purpose is to know if there are some differences when boys and girls join in the language 
activities at home.

\section{Recording}

Recording is a necessary way to construct the corpus. We choose the voice recording pen as the tool for recording, because it is so small that children cannot find it. Then they can speak naturally without distraction. When we record children's conversations, we can choose various topics to stimulate children to talk, such as their toys, entertainment, activities in nursery, and delicious snacks. After recording, we can save them in $\mathrm{mp} 3$ format.

\section{Data collection}

It is based on the self-built corpus which comprised of data collected from 33 Mandarin-speaking children. All children are chosen to be within the age around three and a half years old, and there are seventeen boys and sixteen girls whose parents all get the associate degree or above.

\section{RESUlTS AND Discussion}

\section{A. Analysis of Word Frequency of Boys and Girls}

Analysis of word frequency of boys and girls can reveal that the use of word tendency of boys and girls. The frequency of calculation method is in the following:

$$
\mathrm{f}=\frac{\mathrm{n}}{\mathrm{N}}
$$

"f" stands for the frequency of words; " $n$ " is the token of words; "N" stands for the whole number of words that boys and girls uttered.

The table 1 and table 2 show the situations of the use of vocabulary between boys and girls around three and a half years old. " $\mathrm{n}$ " stands for the tokens of words for each part of speech, and "N" represents the total number of words of boys and girls, that is 21101 .

TABLE 1

THE STATISTICS OF WORDS USE OF BOYS

\begin{tabular}{|l|l|l|l|}
\hline Function of words & Types of words & Token of words & Frequency \\
\hline Nouns & 719 & 1852 & 8.7768 \\
\hline Verbs & 386 & 3123 & 14.8002 \\
\hline Adjectives & 78 & 631 & 2.9904 \\
\hline Prepositions & 18 & 225 & 1.0663 \\
\hline Quantifiers & 35 & 178 & 0.8436 \\
\hline Adverbs & 49 & 863 & 4.0899 \\
\hline Pronouns & 45 & 1426 & 6.7580 \\
\hline Interjections & 30 & 713 & 3.3790 \\
\hline Conjunctions & 8 & 11 & 0.0521 \\
\hline Mood words & 735 & 3.4832 \\
\hline Numeral words & 20 & 101 & 0.4787 \\
\hline Total & 21 & 10458 & 49.5616 \\
\hline Average frequency & & \\
\hline
\end{tabular}

TABLE 2

THE STATISTICS OF WORDS USE OF GIRLS

\begin{tabular}{|l|l|l|l|}
\hline Function of words & Types of words & Token of words & Frequency \\
\hline Nouns & 758 & 2053 & 9.7294 \\
\hline Verbs & 312 & 2532 & 11.9994 \\
\hline Adjectives & 112 & 829 & 3.9287 \\
\hline Prepositions & 17 & 256 & 1.2132 \\
\hline Quantifiers & 23 & 232 & 1.0995 \\
\hline Adverbs & 57 & 1073 & 5.0850 \\
\hline Pronouns & 43 & 2006 & 9.5067 \\
\hline Interjections & 41 & 812 & 3.8482 \\
\hline Conjunctions & 9 & 13 & 0.0616 \\
\hline Mood words & 19 & 668 & 3.1657 \\
\hline Numeral words & 169 & 0.8009 \\
\hline Total & 25 & 10643 & 50.4384 \\
\hline Average frequency & & \\
\hline
\end{tabular}

From the table 1and 2, boys use 1445 types of words, and girls use 1478 types of words, and the total token is 21101 $(10458+10643=21101)$; the frequency of words boys used is $49.5616 \%$, and the frequency of words girls used is $50.4384 \%$; the average frequency of words of boys is $0.0343 \%$, and for girls is $0.0350 \%$. The table shows that girls use more words to communicate than boys, and the frequency of words girls used is also higher than boys'. However, boys can use more verbs and mood words in their speaking, especially the verbs. Different from Li Yuming's research (1995), the results of our research show that boys use more verbs than girls in their conversations. Many researchers found that no matter what gender is, children tend to use nouns rather than verbs. However, Tardif's research (1999) shows that 
boys are good at using verbs because boys are active and they also utter the words to fit in their actions. Tardif even found that the conversation situation plays an essential role in the ration between the verbs and nouns. If giving toys to children, the frequency of verbs is higher. In our experiment, we do not claim whether parents can give the toys to children or not. Since boy's language communication ability is weaker than that of the girl, boys often use mood words to express themselves, which can reduce the chances that they use the new words or difficult words, and this process is an obstacle to the boys' language competence.

B. Results of MLU (Mean Length of Utterances) between the Boys and Girls

TABLE 3

THE MLU BETWEEN BOYS AND GIRLS OF 3-4 YEAR

\begin{tabular}{|l|l|l|l|}
\hline Gender & The number of sentence & The number of words & The MLU \\
\hline Male & 3412 & 14316 & 1.675 \\
\hline Female & 3489 & 16325 & 2.898 \\
\hline
\end{tabular}

The table 3 shows that boys can speak 3412 sentences, and girls can speak 3489 sentences. The number of MLU of boys is 1.675 , and girls is 2.898 . However, we cannot conclude that girls are better than boys in verbal communicative skills just from this table. Independent t-test has to be conducted to examine if there are significant differences of the MLU between boys and girls.

The researcher also analyzes the results of the independent t-test of mean length of utterances between boys and girls.

TABLE 4

INDEPENDENT T-TEST OF MEAN LENGTH OF UTTERANCES OF BOYS AND GIRLS

\begin{tabular}{|l|l|l|l|l|l|l|l|}
\hline Gender & Number & Average Age & Std & t & Mean Difference & df & sig \\
\cline { 1 - 5 } Male & 16 & 3.5 & .3071 & -11.86 & -1.31 & 18 & .001 \\
\cline { 1 - 5 } & 17 & 3.6 & .0952 & & & & \\
\hline
\end{tabular}

In order to compare children's mean length of utterances of boys and girls, the researcher used the Independent-samples t-test to analyze the result. The data in the above table indicated that the boys and girls demonstrated significant differences of mean length utterances at the 0.05 level according to independent T-test. From the mean difference -1.31 (see Table 4) and the p value $0.001(\mathrm{p}<0.05)$, it could be concluded that boys' MLU is lower than girls', and it shows that girls are better at verbal communication than boys according to the results of comparison of MLU between boys and girls.

The table 3 and 4 show that girls' mean length of utterances is longer than boys'. Our research only calculated the words that children utter vocally, however, in practical conversation, many children like using the non-verbal language to express their ideas. Especially for boys, they are good at using actions and gestures to dialogue with others. Relatively, girls tend to use verbal words to express themselves rather than use the actions because of their shy personality. From this aspect, we can only say girls are better to use the verbal words to express themselves, and we cannot conclude girls' language ability is superior to boys', because language ability not only includes the verbal expressions but also the understanding of the language.

\section{The Strategies to IMPRove COMmunicative SKILlS}

The results conducted above indicate that there are some linguistic differences between boys and girls, and girls' language proficiency is better than boys'. Based on the observation and interview, combined with the experimental results, some advice will be come up with to serve as improving boys' language proficiency. Besides, such suggestions may be helpful for children with language obstacles.

\section{A. Settings of Children's Language Environment}

Whether it is the behaviorist view, the innatist view, or the cognitive view, they all take the linguistic environment as a key factor to influence children's language proficiency although the degree to which they stress its function differs. In the behavioristic theory, linguistic environment influence language acquisition directly. In the innate theory, linguistic input serves as a trigger that activates LAD. In the cognitive theory, it interacts with the brain, and plays an indispensable role in language acquisition. Language environment bears remarkable relevance to child language development. If there is nobody speak to a child, this child is separated from language environment, then it is impossible for this child to acquire any word. Studies of feral and isolated children have provided some evidence. In addition, language environment plays a key role in language learning, especially for children whose ages are are around three and a half years old. Since boys' interactive ability is inferior to girls', a positive language environment should be built for boys, which cannot only stimulate them speak fluently and correctly, but also can enrich their language materials.

a. Comprehensible input should be emphasized to improve boys' communicative skills.

The role of input is of great importance in child language acquisition. Without speech input, children cannot acquire language. However, input has its restricted nature since the input a child receives may only have a limited sample of sentence types, or input itself cannot provide all the overt information of sentences. What kind of language input can 
efficiently facilitate children's language acquisition process? According to Krashen, an expert specializing in language acquisition theories, "An acquirer can move from a stage I (where I is the acquirer's level of competence) to a stage I+1 (where $\mathrm{I}+1$ is the stage immediately following I along some natural order) by understanding language containing I +1 ." (Krashen and Terrell, 1983:32) That is, linguistic input that is a little beyond the acquirer's current level of competence can best facilitate his language learning. This is Krashen's input hypothesis. Based on Krashen's input hypothesis, parents and teachers should make children learn language step by step, not only considering their current level of language competence, but also taking their ages and genders into account.

Since boys are poor in interactive skills compare with girls, more language materials should be input to boys, and make more chance to output. Boys' communicative skills can be improved progressively. The input contains aural input and visual input and most of the input exposed to children is aural input. However, no child can learn language passively only by listening to the radio or watch TV. It is because language learning relies on frequent one-on-one contact with an adult or an older partner who provides conversations, questions, comments etc. Conversations between children and adults usually follow the "here-and-now" principle. Parents can use speech that directs attention to particular aspects of their messages. Evidences from studies conducted by Cross (1978), Ellis and Wells (1980), and Barnes et al. (1983) shows that the way parents talk to their children influences the speed and characteristics they acquire the language. Therefore, to foster boys' communicative ability, parents should give them efficient language input, because language heard but not addressed directly at the boys does not help. There are some tips for parents to improve boys' language ability: Firstly, repeated words tend to be shorter, quieter, lower-pitched, and less variable in pitch than first-mentioned words (Fisher and Tokura, 1995); Secondly, parents should speak in a way that highlights attention on new words or sentences at the expense of older words or sentences, and boys' current linguistic level should be considered; lastly, boys should be encouraged in participating in adults' conversations, if parents find boys are not interested in adults' conversations, they can change their topics to cater for boys' interests. For example: transportation (cars, buses, trains, ship, plane and so on), their favorite toys (robots, transformers, balls......) and some natural phenomena (rain, thunder, wind, rainbow and snow). According to our interview, we find if parents can talk something that boys are fond of, they can be involved in the conversations quickly.

\section{b. Leading children to communicate with others.}

How to make children speak smoothly? How to lead children to speak logically? Especially for boys who always keep silent lose many opportunities to express themselves. Finding some interesting topics or asking relevant questions to them, which can arouse them speak freely and automatically.

\section{Leading children to narrate what happened in a day.}

In our experiment, there is a boy named Fan Junchen who are good at communicating with others, in that he always chats with his teacher and tells the teacher what he did at home, he could even completely narrate the story for his classmates in the nursery when he was just three years old. The interview of Fan Junchen's parents indicated that his mother paid more attention to the cultivation of his language expression at his early age. The most frequently used way the mother adopts is that personal narrative. When the boy was only 20 months, his mother used this way to lead him speak even though the boy could not speak the complete sentence. His mother just gives us an example to show how she leads her son to speak:

MOT: Where have you been today?

CHI: Great grandpa's home.

MOT: Who did you go with?

CHI: Grandma.

MOT: Is it funny at Great grandpa's home?

CHI: Yes.

MOT: Who brought you out to play?

CHI: My aunt.

MOT: Where did you go?

CHI: Downstairs.

MOT: Did you play with other children?

CHI: No.

MOT: Are the foods tasty in Great grandpa's home?

CHI: Very delicious!

MOT: Which food did you like most?

CHI: Meat.

MOT: Will you go there next week?

CHI: Yes.

From the above example, this mother uses some simple questions to lead the boy to narrate what he did at his grandma's home. Considering his age, the following points should be paid attention to: Firstly, questions should be simple, and children can use only less than five words to answer. Secondly, parents would better obey the time sequence when asking questions, so that children can have a clear thinking when answering the questions. Finally, when asking questions, the speed and intonation should be taken into consideration. Slow speed and exaggerated intonation may 
arouse children to answer the questions fluently.

For children who are under 3 years old, parents are in dominant role when leading children to speak, parents can use some strategies to stimulate their children to talk. However, for children who are over 3 years old, parents' dominant role should be changed into the secondary role, and children's speaking words are increased greatly. Here is another example about Fan Junchen and his mother's conversation when this boy was three and half years.

CHI: Mum, I was so happy today!

MOT: Why?

CHI: I was praised by the teacher, because I could do something by myself. I put on the clothes and shoes on my own.

MOT: Oh, that's great!

CHI: But Huhu could not, so he was criticized by the teacher.

MOT: Was Hanhan praised?

CHI: No, because she could only put on her shoes, but not the clothes on her own, even she cried loudly today.

MOT: Why?

CHI: She put off her shoes when she had a meal, then the teacher took her shoes away, and she cried.

From this short conversation, we see when Fan Junchen's mother talked to him, she just used a few words to lead Fan Junchen to speak, such as: "oh, then, why". However, Fan Junchen can speak a lot under the guidance of his mother, and we can see he used long sentences to respond to his mother. What's more, he used appropriate conjunctions to connect sentences, for example, because, then, and, furthermore, and however.

Leading children to speak by a story.

Reading a story for children, and asking them some questions that are related to the story. Or after reading the story, parents or teachers can lead children to narrate the whole story. Taking a famous fairy tale "The Little Red Riding Hood" as an example, after reading the whole story for children, the following questions can be adopted for leading children's speaking:

(1) Why was this girl named "little red riding hood"?

(2) What did the little red riding hood's mother tell before she went to her grandma's home?

(3) Whom did the little red riding hood meet in the forest?

(4) Why did the little red riding hood not go to grandma's home directly? And what did she do on the way of her grandma's home?

(5) Why did the wolf pretend the little red riding hood to go to her grandma's home?

(6) How many people did the wolf devour? Who are they?

(7) Who did discover that the wolf swallowed the little red riding hood and grandma? And what did he do?

(8) Where did the little red riding hood go?

Questions mentioned above can examine children's comprehension of the whole story. Children will think and talk according to the questions. In this process, children have to think how to arrange words to answer questions, so this way even stimulates children to talk logically. Although some children cannot answer the questions accurately and smoothly, most of them can understand the whole story and answer the questions exactly if parents can read the story for the second time. They can be absorbed in listening to the story, because they know there is the task (answer the questions) for them after the end of story.

\section{Finding a quiet place to practice the conversation with children}

Parents can find a tranquil place where just mother or father and your child stay at, then the child can pay full attention to talk with their mother or father. If spending 20 minutes everyday, and persevering for only one month, you may find your child's language ability developed greatly. In our experiment, there is a boy who named Zhu Jianyu. his parents adopted this method to improve his language ability, although they just stick to this way for only 19 days, they found that Zhu Jianyu's language ability developed greatly. Before practicing, Zhu Jianyu could also communicate with others without any obstacle, but he could just use some scattered and disorderly words instead of a logic sentence to express his ideas. Based on his parents' interview, we know after taking this method, he can use orderly and logic sentences to talk with others, and he knows how to use proper conjunctions to connect sentences, and find suitable adjectives to modify the nouns. He can even express his ideas like adults. There are some examples that Zhu Jianyu's parents offered to us.

(In Zhu Jianyu's bedroom, Zhu Jianyu is talking with his mother)

MOT: What did you have in the nursery today?

CHI: I had apples and cakes. Besides, I had the noodles and eggs.

In this short conversation, "besides" is a word that Zhu Jianyu never used before the training of conversations with his parents, he knows "besides" can be used for progressive relation.

MOT: Tomorrow is the Saturday, and where do you want to go?

CHI: I want to go to the square or the park.

In this short conversation, "or" is the word that Zhu Jianyu used for the first time, and obviously, he knows "or" can be used in the relation of the choice.

MOT: Don't watch TV today. 
CHI: Why? Today I am so obedient to get the dinner, although I only get a few vegetables, I get a great bowl of rice.

This short conversation shows that "although" is used to express unsatisfied feeling. This boy can choose suitable conjunctions to connect sentences which indicate the adversative relation.

Such several short conversations mentioned above imply that Zhu Jianyu can answer his mother's questions quickly, and the word choice is appropriate, the relationship of sentences is logical and reasonable.

\section{Creating cooperative environment for boys and girls}

Based on our observation, we find that personality is another important factor influencing children's communication. Generally speaking, outward children like communicating with others, so that their linguistic acquisition develops faster than inward children. Our research shows that many girls get easily familiar with others and are willing to talk with people in a polite way, for example, they are proactive in greeting others. Girls prefer to choosing some topics they are interested in, or using some objects they like, so that the adults can have a talk with the girls successfully. However, boys are relatively hard to get along with, let alone have a further talk with them. According to our statistics, there are thirteen girls who can communicate with us pleasantly, only three of them have less talk with us. On the contrary, there are only five boys who communicate with us without difficulty, for the rest of them, some boys always ignore us even if we use the toys and the delicious snacks to stimulate them to communicate with us; some of them can only stammer over several words, and there is no logical meaning among words and sentences. Therefore, parents or teachers should set up a suitable language environment where boys and girls can collaborate to communicate with each other. Girls can use their passion to drive the boys to do the collaborative games. In this process, boys tend to imitate their peers' language and actions, so this is an effective way that can push boys to speak. In addition, outgoing children are more confident and risk-taking and they dare to imitate others' words under any circumstances. Thus, they have more opportunities to learn vocabulary. On the opposite, inward children are shy and timid. They tend to be more careful and conservative in using language, so that they lose a lot of chances to learn words. Therefore, the number of words that outward children and inward children acquire differs.

\section{B. Improvement of Cognitive Ability}

Children's cognitive ability is closely related to their language ability, and child language development should be based on the accumulation of experience and improvement of cognitive ability. Children's cognitive development is the process from the concrete to the abstract, so does the language development. There exist some differences in the development of children's cognitive ability, which may improve or hinder child language acquisition. Through the observation and interview, we find the more experiences children obtain, the higher interactive ability they possess. Therefore, the way to improve boys' cognitive ability can make up for their inferiority of language ability. There are some positive ways which can be adopted by parents and teachers.

a. Traveling is a positive way to improve children's cognitive ability. For boys, their personality is bravery, adventurous and challengeable, so traveling is undoubtedly a good means to enrich boys' knowledge and experiences. When traveling, boys are always excited, and they always think when they contact new things in the process of traveling, therefore, they can easily remember the names of new places. After traveling, they are eager to talk about what they see and what they experience to others. Mo Jingyan's mother told us Mo Jingyan became talkative after the traveling. She even found Mo Jingyan could use more words and long sentences to express his traveling experience. According to Mo Jingyan's teacher, Mo Jingyan was unwilling to talk to other classmates in the nursery, however, after the traveling, he always tries to communicate with his classmates, and he can even tell every place's name he went during the traveling. For example, Chendu, Dujiangyan, Huanlegu, Emeishan and so on. Why can he memorize such names accurately, and speak them clearly? That is undoubtedly due to his traveling experiences. During his traveling, he saw what he was fond of, he touched what he was interested in, he was attracted by what he never saw, or he felt excited because of fresh things. Therefore, it demonstrates that children's memory and language is closely connected with their experiences, that is to say, children's expressive ability is affected by what they see, touch and feel.

b. To improve children's cognitive ability, the cultivation of the imaginative, and creative ability is very important. Children's language ability is associated with their imaginative ability as well as creative ability. According to Zhou Jing, if children always imagine what will happen, they will have more language materials to express, and their imagination is the stimulus which pushes ahead with language development. Most boys may have strong imaginative ability, so parents should cultivate boys' language ability based on the way of the cultivation of imaginative ability. There is a related way that the parents offer to us: using the pictures to make boys think and speak. For example, there are two trees, a house and a dog in a picture, and parents can ask their sons to describe what they can see in the picture. Then parents may let their sons to make up a story based on this picture. In this process, parents should encourage sons to exert imaginative ability to talk about what they can think.

c. To enrich boys' life experience is an effective method to develop their language ability. Abundant life experience is the source for children to communicate. For boys, parents should help them to accumulate life experience, even at home. Therefore, parents should encourage boys to get experience from household affairs to fresh things outside. Zhou Jing once pointed out the reason why girls are good at talking to others lies in the focus of their attention. Parents often talk to girls concerning household affairs while most parents do not want to talk such affairs to boys, because this is Chinese traditional ideas that boys should not pay more attention to household affairs. However, from children's cognitive development, they tend to be interested in the household affairs due to the familiarity, if parents can input more 
language about household affairs, children can acquire such kinds of language quickly. Therefore, girls have more language materials to output than boys. In fact, some traditional ideas obstruct boys' language ability.

\section{CONCLUSIONS}

From studying the gender difference of child language acquisition, the author finds that cognitive view and gender differential language of children play an essential role in it. According to the results of our research, the author comes up with some effective methods to help boys to overcome their linguistic weakness. Stimulus or linguistic input, response, imitation and practice are indispensable for boys to acquire language easily. In the language acquisition process, children actively use their brain and cognition to acquire the language including exploration of the words' usage, sentence formation and narration of occurrence. However, the claim that there is a language acquisition device or universal grammar in the child's brain is doubtful. Both the behaviorists and the innatists have gone to extreme in their theories. On the contrary, the cognitive theory is the most convincing and scientific one. It gives us the insight into the gender differences of child language acquisition. Besides, we can see that linguistic competence is acquired through the interaction of the environment and the biological conditions. Many researchers try to explore the linguistic characteristics of boys and girls respectively, and then find the linguistic differences according to biological differences.

\section{A. Research Findings}

Based on the quantitative research, the following three major findings can be summed up:

a. Boys and girls' linguistic differences may depend on the structures of brain to some extent, because boys tend to use the half hemisphere of the brain to think while the girls often use both hemispheres to think. Since the left hemisphere control people's language most, so boys' language ability develops later than girls' due to the different biological structures. Besides, the findings also suggested that children's language ability will be influenced by their cognitive ability.

b. There indeed exist some linguistic differences between boys and girls around the age of three and a half years old in our research. On one hand, from the comparison of high frequency words between boys and girls, we find boys tend to use verbs, quantifiers and interjections while girls tend to use adjectives, pronouns and mood words. It attributes to the different language environment, cognitive modes, personality, and the number of language input. On the other hand, after the experiment, the researcher finds there are significant differences of mean length of utterances between boys and girls, and the MLU of girls are longer than boys.

c. The data from our research indicates boys' language ability can be improved if parents and teachers give them more chances to practice. And from the way of imitation, reciting, narration, retelling and interesting conversations, boys' interactive ability will be developed quickly. Only if parents can pay attention to cultivate their communicative skills, will boys also have excellent performance in language acquisition.

\section{B. Implications for Teachers and Parents}

The findings of the studies seem to have important implications for nursery teachers, parents and language researchers. The fact is that there are indeed some linguistic differences of boys and girls around the age of three and a half years old. The researcher provides some useful and practical ways to help boys make up for their language defects. So it is vital for parents to be aware that the linguistic differences between boys and girls lie in their brain structures, cognition, interests and language environment. Then parents and teachers can consciously design appropriate methods for boys to improve their interactive skills.

\section{Limitations of the Present Study}

After discussing the implications of the study, it was important for the researcher to outline the limitations of the study. The study has its own limitations except its strengths, due to which the present research was only a tentative one, leaving too much room to improve.

Firstly, it is hard to collect data of children's speaking, because we have to consult with their parents and teachers, and in the recording process, if children are tired or want to discontinue the activity, we should respect their wishes, and take a break or return at another time to complete the investigation. Besides, it is possible that their parents perfected their children's speech. Perhaps the parents could not remember their children's original words and then expressed their children's meanings in another way.

Secondly, to the limited capacity of the researcher, the sample sizes we choose are relatively small, and our recordings of children's conversations are for only brief periods.

Thirdly, this study only concentrates on the comparison of linguistic characteristics of different genders, despite of children's linguistic characteristics in different ages.

\section{Suggestions for Further Study}

To overcome limitations of this research, the present researcher puts forward the following suggestions: Further studies should contain large and consistent samples, carefully explained procedures. It is notable that this research only reveals linguistic differences between boys and girls around the age of three and a half years old in frequency of the word class and mean length of utterances. Therefore, further research should involve in other fields about child 
language of different genders, including the comparison of errors, self-initiated repairs, and child directed language.

\section{REFERENCES}

[1] Anderson, R. \& Shirai, Y. (1994). Discourse motivations for some cognitive acquisition principles. Studies in Second Language Acquisition, 16(1), 133-156.

[2] Brown, D. (2002). Principles of Language Learning and Teaching. Beijing: Foreign Language Teaching and Research Press.

[3] Chomsky, N. (1968). Language and mind. New York: Harcourt Braced Jovanovich.

[4] Chomsky, N. (1995). The Minimalist program. Cambridge, MA: MIT Press.

[5] Cook, Vivian and Mark Newson. (2000). Chomsky's universal grammar: An introduction. Beijing: Foreign Language Teaching and Research Press.

[6] Foster-Cohen, Susan H. (2002). An introduction to child language development. Beijing: Foreign Language Teaching and Research Press.

[7] Lakoff, R. (1975). Language and women's place. New York: Harper \& Row.

[8] Lenneberg, E.H. (1967). Biological foundations of language. New York: John Wiley \& Sons.

[9] Maccoby, E. E. \& Jacklin, C. N. (1974). The psychology of sex differences. Standford: Standford University Press.

[10] MacWhinney, B. (1995a). The CHILDES Project: Tools for analyzing talk. Second Edition. Mahwah, NJ: Lawrence Erlbaum Associates.

[11] MacWhinney, B. (2000b). The CHILDES Project: Tools for Analyzing Talk. Third Edition. Mahwah, NJ: Lawrence Erlbaum Associates.

[12] Nohara, M. (1996). Personal boys and girls use no differently. Child Language, 23(2), 417-429.

[13] Paradis, J. (2007). Bilingual children with specific language impairment: theoretical and applied issues. Applied Psychology, 28, 551-564.

[14] Pearson, B. Z. et al. (1997). The relation of input factors to lexical learning by bilingual infants. Applied Psycholinguistics, 18, 41-58.

[15] Piaget, J. (1955). The language and thought of Child. Cleveland, OH: World.

[16] Piaget, J. and Inhelder, B. (1969). The psychology of the Child. New York: Basic Books.

[17] Tardif, T. (2006). But are they really verbs? Mandarin words for action. In K. Hirsh-Pasek, R.M. Golinkoff (Eds.), Action meets word: How children learn verbs. Oxford: Oxford University Press.

[18] Thierry Nazzi \& Josiane Bertoncini. (1997). Before and after the vocabulary spurt: two modes of word acquisition? Journal of Child Language, 24(2), 535-565.

[19] Zhou Jing. (2001). Preschool children's language education. Naijing: Nanjing Normal University Press.

Yingying Ma was born in Guizhou Province, China in 1981. She finished her MA in Foreign and Applied Linguistics in Guizhou University, China in 2013. She is currently a visiting scholar in the School of Education and Human Services, Oakland University, Michigan, US. She is an associate professor in English Teaching at Zunyi Medical University. Her research field includes child language acquisition and second language teaching. 